\title{
Ihr Feedback ist uns Ansporn
}

Ihre Meinung ist uns wichtig. Deshalb haben wir in der April-Ausgabe der pädiatrie hautnah eine Leserbefragung mit acht Fragen zum Heft durchgeführt. Parallel wurden Pädiater auch online auf der Plattform von Springer Medizin (www.springermedizin. de) zu ihren Wünschen bezüglich pädiatrischer Fachzeitschriften befragt. Insgesamt 372 Leserinnen und Leser nahmen an der Umfrage teil. Wir haben uns über Ihre guten Bewertungen gefreut und werden Ihre Lieblingsrubiken auch weiterhin bedienen.

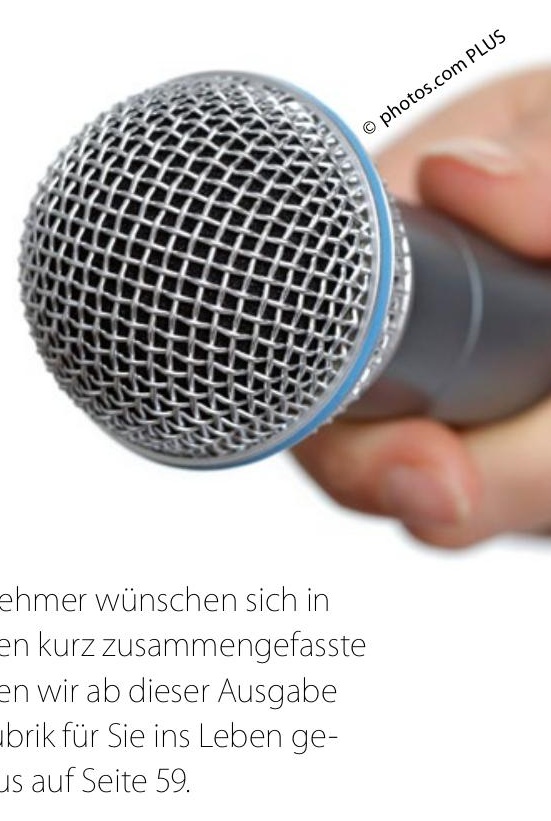

Wie beurteilen Sie die Zeitschrift pädiatrie hautnah insgesamt auf einer Skala von 1 (ausgezeichnet) bis 5 (schlecht)?

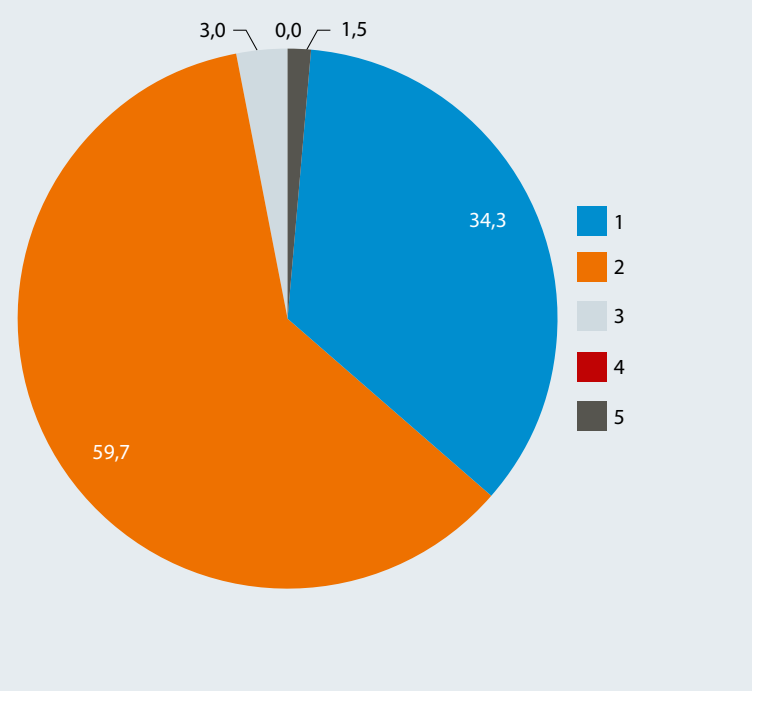

$93 \%$ der Teilnehmer wünschen sich in Fortbildungszeitschriften kurz zusammengefasste Leitlinien. Deshalb haben wir ab dieser Ausgabe eine entsprechende Rubrik für Sie ins Leben gerufen: Leitlinien im Fokus auf Seite 59.
Die Eigenschaften, die die Befragten mit der Zeitschrift pädiatrie hautnah verbinden (bewertet mit "trifft voll zu“ und "trifft zu")?

\footnotetext{
_ Aktuell (90\% der Befragten)

_ Übersichtlich und lesefreundlich (88\%)

_ Seriös (87\%)

_ Wissenschaftlich (73\%)

_ Praxisrelevant (91\%)

_ Ansprechend gestaltet (85\%)

_ Entbehrlich (7,5\%)
}

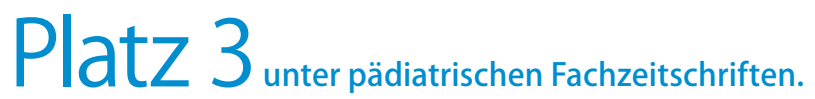

Bei der online gestellten Frage „Welche pädiatrische Fachzeitschrift lesen Sie am liebsten?" platzierte sich die pädiatrie hautnah nach der Monatsschrift Kinderheilkunde und dem Kinder- und Jugendarzt auf dem dritten Rang.

\author{
Die Lieblingsrubriken der Leser \\ (die Rubriken, die mit "gefällt mir sehr gut" und \\ „gefällt mir gut" bewertet wurden) \\ Kasuistiken (85\%), Fundstücke (81\%), Literatur \\ kompakt (79\%), Im Blickpunkt (79\%), Fortbildungs- \\ beiträge (79\%) und Blickdiagnose-Quiz (78\%)
}

Wir bedanken uns bei allen Teilnehmern.

Die Preise wurden den Gewinnern bereits zugesendet. 